\title{
Non-invasive measurement of photosensitiser concentration using fluorescence differential path-length spectroscopy: validation for different liposomal formulations of $m$-THPC: Foscan, Foslip and Fospeg
}

\author{
Sebastiaan de Visscher*, Max Witjes, Slávka Kascáková, Dominic Robinson, Henricus Sterenborg, Jan Roodenburg, \\ Arjen Amelink
}

From 2nd Scientific Meeting of the Head and Neck Optical Diagnostics Society

San Francisco, CA, USA. 23-24 January 2010

As previously described, Fluorescence differential path length spectroscopy (FPDS) can determine chromophore concentrations non-invasively after injection with $\mathrm{m}$-THPC (Foscan) in the rat liver [1]. Our first aim is to validate FDPS for two other, liposomal formulations of $\mathrm{m}$-THPC; pegylated liposomes (Fospeg) and conventionel liposomes (Foslip), and compare them to Foscan. As a proof of principle we use the highly vascularised, optically homogenous liver of the rat [1] Validation of the FDPS-measurements was done by chemical extraction of the same liver [2].

Our second aim is to validate FDPS measurements of the tongue, which is optically less homogenous, but clinically more relevant. After successful validation in both liver and tongue tissue, the pharmacokinetic-profile in other tissue types could be assessed by FDPS alone. Therefore, FDPS can lower the need for labour-intensive chemical extraction. Fifty-four male Wistar rats were intravenously injected with one of the three formulations of m-THPC; eighteen rats for each formulation. All rats were injected with $0.15 \mathrm{mg} \mathrm{kg} \mathrm{m}$-THPC. FDPS measurements were performed on liver, palate, tongue, spleen and kidney 2, 4, 8, 24, 48, and $96 \mathrm{~h}$ after $\mathrm{m}$-THPC administration. For validation of our FDPS measurements, liver and tongue were harvested for chemical extraction [2]. Concentration estimates in liver and tongue measured by FDPS are here compared with chemical extraction.

At the HNODS-meeting we will present the results of our first step in the validation of FDPS; the correlation of FDPS measurements with chemical extraction for the three different formulations in the liver.

Published: 29 October 2010

\section{References}

1. Kruijt B, Kascakova S, de Bruijn HS, van der Ploeg-van den Heuvel A, Sterenborg HJ, Robinson DJ, Amelink A: In vivo quantification of chromophore concentration using fluorescence differential path length spectroscopy. J Biomed Opt. 2009, 14(3):034022.

2. Kascáková $\mathrm{S}$, Kruijt B, de Bruijn HS, van der Ploeg-van den Heuvel A, Robinson DJ, Sterenborg HJ, Amelink A: Ex vivo quantification of mTHPC concentration in tissue: influence of chemical extraction on the optical properties. J Photochem Photobiol B. 2008, 91(2-3):99-107.

doi:10.1186/1758-3284-2-S1-046

Cite this article as: de Visscher et al:: Non-invasive measurement of photosensitiser concentration using fluorescence differential pathlength spectroscopy: validation for different liposomal formulations of m-THPC: Foscan, Foslip and Fospeg. Head \& Neck Oncology 2010 2(Suppl 1):046. 